itself, and, with the concurrence of $\mathrm{my}$ friend, Mr. Randall, of Oiford, who kindly rendered his assistance, I resolved to give this plan a trial before resorting to the ultima ratio of the knife.

Accordingly, a common enema having been previously administered, I introduced the cesophagus tube of Weiss's stomach-pump with tolerable facility, until it arrived (as nearly as I could judge) at the sigmoid flexure of the colon, where it encountered some degree of resistance, which yielded, however, in a short time, to moderate pressure, after the injection of a little cold water. The tube was now passed gradually up until its whole length, about twenty-five inches, had been introduced, the brass extremity alone remaining without.

After waiting a quarter of an hour, between two and three pints of water were thrown up and retained in the bowel for a short period; the cylinder of the pump having been unscrewed from the elastic tube, and the mouth of the latter closed by the thumb, on withdrawing which the fluid repassed in a jet of considerable force. The cylinder was now readjusted to the tube, and the action of the machine being reversed, the piston was worked rapidly with the view of producing a degree of exhaustion or partial vacuum in the intestine; gentle taxis was at the same time resumed, and after the expiration of four or five minutes (during the latter part of which the patient complained of a sensation of bearing down referred to the whole abdominal region), I had the satisfaction to feel the contents of the tumour recede from beneath my fingers, and slip into the abdomen with the usual gurgling which accompanies the return of intestine.

The man recovered without an untoward symptom, and was removed to his father's house at Wickham, a distance of about nine miles, on the third day afterwards.

I am disposed to attribute the successful result of the foregoing case, in a principal degree, to the production of a partial vacuum in the intestine immediately below the seat of strangulation, by the exhausting process, that being the direct agent to which the obstruction appears to have yielded; and $I$ am induced to recommend a trial of this measure to the profession as an adjuvant to that valuable instrument, the elastic tube, in cases where the latter alone may prove inefficient.

I have since reperused Dr. O'Beirne's excellent work on Defacation, with the view of ascertaining whether exhaustion through the tube had been adopted in any of his cases. I cannot discover that the doctor has availed himself of this expedient, although a case of constipation is cited by him in which a Dr. Duguid, of Kirkwall, in Scotland, introduced an elastic tube into the colon with the effect of discharging an accumulation of fæces; and I observe that this gentleman attempted to exhaust with the view of overcoming the resistance he experienced to the passage of the tube at the sig. moid flexure, but unsuccessfully, which circumstance induced him to undervalue the measure. There is, however, another case which seems to have suggested to Dr. Duguid the use of the tube, and which is reported in the Medical and Physical Journal, for December, 1827, being communicated by Dr. James Johnson, as having occurred in February, 1826, in the practice of Dr. Alexander, of Genoa, who appears to have em. ployed exhaustion through a hollow bougie, after twelve days of constipation, and the failure of tobacco enemata and various other remedies, with complete success. This case, which is a very interesting one, seems to have excited but little attention.

I cannot conclude without expressing my conviction (in nearly the words of Dr. O'Beirne, who uses them, however, with reference to the tube only) that no surgeon is justified in proceeding to the operation for strangulated intestinal hernia, without having previously given a fair trial to the measures above alluded to.

\section{THE SETON IN CHRONIC DISEASE} OF THE BRAIN.

\section{To the Editor of $\mathbf{T}_{\mathrm{He}} \mathrm{LanceT}$.}

Sir,-Should you consider the annexed case worthy of insertion in The LANCET, I shall feel obliged by your giving it publicity. I remain, Sir, your obedient servant,

W. B. Barton, M.D.

Horncastle, May 5, 1842.

Mr. T., aged 64 years. Visited September 27,1841 . Took cold in the summer of 1839 from sleeping on damp grass, in a field, which induced fever with acute inflammation of the brain. His usual medical attendant was promptly summoned, and the early treat. ment, it would seem from the report and its effects, was active and judicious, the ferer and acute inflammation subsiding in a few days. There remained, however, an obtuse pain in the head, without fever, and sliglt mental obscuration. The latter, notwithstanding the continued administration of remedial asents, increased gradually, until at length Mir. T. became perfectly childish aud idiotic.

At the time of my first visit (Sept. 2i, 1841, he did not know the different members of his family, could not converse at all, and scarcely speak intelligibly; did not clearly uuderstand any ordinary questions put to him, and spent his days in a chair by the fireside (cold evers on a bright midsummer's day), in a state of pitiable fatuity. The gradual annihilation of the mental powers, accompanied by a simultaneous de. cay of the corporeal functions, had brought 
him apparently to the very verge of the grave.

On carefully reviewing the previous treatment and the present symptoms, I certainly formed a most unfavourable prognosisdeath the ullimate result. However, I ordered nourishing diet, mild aperients as occasion might require, and the insertion of a seton at the nape of the neck.

The discharge from the seton once properly established, an amendment was shortly perceptible; in the course of ten days a few faint rays of pristine intellectual vigour dawned, and the corporeal functions responded simultaneously. Progressively the disease yielded, and in the course of five weeks my patient again became an useful member of society.

I called on the 2 nd Dec. following, when $I$ found him engaged on his farm, in the full enjoyment of his intellectual powers, looking well and healthy. He stated that he had no recollection of having seen me in September, and that he was not sensible of the insertion of the seton.

About the middle of April the seton was withdrawn, my patient being in the enjoyment of perfect health, as well mental as corporeal, which has continued to this day.

\section{THE RESULTS AS AFFECTING} THE

EUROPEAN PORTION OF THE ARMY THAT LANDED AT RANGOON, DUPING THE

\section{LATE BURMESE WAR OF 1821-5-6.}

1st. It is now well known that the climate of the Teuasserim provinces, occupied by British troops since 1825, is not inimical to European health; and there can be no doubt that similar results would have been obtained in regard to Rangoon, had the circumstances under which our troops served there been equal. But the war was declared, by the Government of the day, in the month of March, consequently the meat provision for the troops was to be cured under a temperature so high as to render a partial de. composition of it probable, even before the meat could have taken in the salting, and such was found to be the fact in serving out the provisions immediately on the landing of the expedition at Rangoon in May.

2ad. Rangoon was occupied by the British force on the 11th of May, 1821, and it broke ground for the advance into the interior on the 11th of February, 1825; consequently it remained in position at Rangoon, and was actively employed in field operations around the town during nine months, five of which were included in the south-west rainy monsoon of the country.

3rd. The sickness and mortality of the British soldiers during the nine months here No. 978 . specified were such as never before occurred in any recorded $B$ ritish expedition, and such as are believed to be altogether unknown to modern warfare; for, out of an aggregate of 3004 men, there were admitted into hospital 10,646, or the proportion of 3556 per thousand; in other words, every soldier was attacked by disease three or four times; while the deaths in six corps, in eleven months, were 2000 , exclusive of the Madras European regiment. Altogether the deaths nearly equalled the number of British troops originally employed; and, but for seasonable reinforcements, the objects of the expedition must have failed from the entire annihilation of the force.

4th. It is useful to compare the results of the Burmese with those of European war, because there is no other mode whereby the authorities, with whom rests the ultimate reward of the soldier, can know the risk of life and peril of constitution by which his pension has been earned. On this view I will state briefly, on the authority of the statistical reports of the army, prepared by Major Tulloch, and printed by order of Par. liament, that during a period of 41 months in which the Peninsular war was prosecuted. with the utmost vigour, " 4 per cent. occurred in battle, or of wounds, which proved fatal within a few days thereafter, and 12 per cent. was from disease and other causes ;" whereas, in the first year of the Burmese war, $3 \frac{1}{2}$ per cent. were killed in action, and 45 per cent. perished by disease-making a total loss of 48 per cent.; consequently, each person employed throughout that year encountered more risk of life than in three Peniusular campaigns. In the second year of the war the proportion of deaths in action or by disease, was only about one-half of what occurred in the first; but even then the risk of life was considerably more than during a similar period of the most severe service in the Peninsula." In short, 72 per cent. perished in these two yeal"s."

5th. The causes of so appalling a loss were-defective arrangement for the supply of food; the making war at the worst instead of the best season, so as to cause a most umnecessary exposure and fatigue; the want of necessaries and comforts for the sick in hospital, who had for months to subsist, under the pressure of aggravated disease, on tainted salt rations, until scurvy was added to the catalogue of misfortune, - a scourge which at length infested the whole army, those on duty as well as those who crowded the hospitals.

6th. It is not pretended that the experience of an invadiug army can any where be assumed as a correct standard for estimating the influence of climate; but the fate of the Rangoon expedition proves that, in a climate esteemed by all superior to that of India, the most fatal results are sure to follow the absence of a due provision being 